\title{
Imagining, seeking, inventing: the future of learning and the emerging discovery networks
}

\author{
Gary Natriello
}

Received: 2 January 2007 / Accepted: 10 January 2007/ Published online: 6 March 2007

(C) Springer Science+Business Media, LLC 2007

\begin{abstract}
Extrapolating from current developments in the study of learning and imagining how learning might be shaped moving forward, this article considers 12 trends concerning the future of learning. Learning will become more diverse, more contextual, less discipline-bound, and less institutionally-bound. It will span professional and institutional sectors, and move beyond national borders. It will move increasingly online and extend beyond humans to encompass machines and machine/ human blends. It will become more interactive, more distributed, and more biologically connected. Drawing on an understanding of these trends, new roles for teachers and for educational institutions are developed. The result is that learning is likely to occur through multiple discovery networks that blend research and teaching to address real world problems in environments supported by robust software infrastructures. Multiple nested discovery networks will operate on a global scale and be negotiated by individual learners sometimes guided by teachers.
\end{abstract}

Keywords Future of learning - Contextual learning · Life-long learning · Trans-disciplinary learning $\cdot$ Trans-national learning $\cdot$ Online learning

Prediction is very difficult, especially about the future-Niels Bohr

The future is already here - it's just unevenly distributed-William Gibson

The best way to predict the future is to invent it-Alan Kay

The quotes above suggest three quite different strategies for thinking about the future of anything, including the future of learning. Niels Bohr reminds us that predicting is a very difficult business with mixed results at best. The implication that

G. Natriello $(\bowtie)$

Teachers College, Columbia University, 525 W. 120th Street, Box 85, New York,

NY 10027, USA

e-mail: gjn6@columbia.edu 
I draw for the present exercise is that it might be useful to allow for more than a bit of imagination to shape the prediction process. William Gibson advises us to examine the present broadly for clues as to the dominant themes of the future. From this I take the need to consider current practices especially when they are at the margins and perhaps beyond common recognition. Alan Kay offers the most ambitious perspective when he tells us that we can bring about the kind of future that we are willing to work toward. From this I claim the right to impose a bit of our own aspirations to create the future we desire. So, what follows is a combination of what we simply do not know and can only imagine, what has appeared somewhere already, and what we might hope to make happen with enough of our own energy and time.

Since a definition of learning may be the only stable element in the discussion, it seems essential to begin with a clear definition. Accordingly, I will assume that learning refers to the processes through which organisms or entities gain an understanding that influences them to change their attitudes and/or behaviors. While this definition may not be to everyone's tastes, it will serve well for thinking about the kind of future possibilities I have in mind.

\section{Trends in learning and the implications for the future}

Clues to the future of learning surround us if we can only spot them. Some are more prominent than others, and, of course, there may be big surprises connected to things we currently cannot see. I will begin with the current trends that promise to shape the future of learning in substantial ways and conclude with a discussion of the types of approaches that will allow us to push our understanding of learning beyond the bounds of current research.

Trend 1-learning is becoming more diverse

Learning is becoming more diverse, or at least our understanding of how learning occurs is revealing a more diverse set of learning opportunities than we have typically highlighted in the past. As a result we are more attuned to the variety of learning opportunities and circumstances that pervade human experience.

We increasingly recognize that individuals learn throughout their life-cycle (Gorard \& Selwyn, 2005; Rees, Fevre, Furlong, \& Gorard, 1997). Old notions of limitations on the timing of learning are giving way to the view of that learning is a cradle to grave phenomenon.

We have come to understand that learning takes place in multiple settings and contexts, including the workplace (Gherardi, 2006; Marsick, 1987), the family (Goodfellow \& Lamy, 1998; Lochrie, 2004), the community (Ball, 1995; Melaville, Berg, \& Blank, 2006), and the church (Jarvis, 1994). Learning takes place in these settings in both deliberate and informal ways, and it is essential to the operation of all organizations.

A growing appreciation of diversity in learning also extends to individual learners who present substantially different learner profiles to which educational approaches must respond to achieve optimal learning outcomes (e.g., Fields \& Shelton, 2006; Sohn, Doane, \& Garrison, 2006). There is substantial evidence contributing to our understanding that individuals come to learning new things with diverse 
backgrounds of experience and prior understandings that must be engaged for additional learning to occur (Bransford, Brown, \& Cocking, 2002).

\section{Trend 2-learning is becoming more contextual}

Our understanding of learning is becoming less isolated within individuals or even within the dyadic relationship of learner and teacher. Learning is increasingly understood to be linked to specific contexts to which individuals are connected in powerful and important ways. This view of learning places the learner at the center and always embedded within a specific environment or context that affects learning opportunities (Palfreyman, 2006)

The more contextual understanding of learning and learning opportunities is leading to several important research directions. First, there is an interest in understanding the contextual conditions that promote learning. So, for example, within organization settings factors such as decentralized planning and employee participation in decision making are receiving attention for their contributions to employee learning (Perez, Peon, \& Ordas, 2006).

Second, beyond such specific factors, there is an interest in developing a social structural understanding of learning environments. For example, the evolving literature on the strength of weak ties is prompting a more social structural understanding of learning environments (Carolan \& Natriello, 2005; Levin \& Cross, 2004).

The end result of the growing appreciation of contextual factors is that learning appears increasingly more susceptible to environmental factors no matter where it occurs or where we seek to investigate it. This means that examinations of learning across a range of settings will come to focus more effort on the learning potential of those settings. It also means that efforts to configure environments to promote learning and discovery are likely to gain momentum in the years ahead.

\section{Trend 3-learning is becoming less discipline-bound}

Although the disciplinary categories into which we divide knowledge and approaches to discovery are useful for understanding the work of scholarship and science, these categories are less useful as lenses through which to understand how individuals learn more generally and as strategies for organizing learning opportunities. Interdisciplinary learning opportunities lead to more powerful student learning (Ivanitskaya, Clark, Montgomery, \& Primeau, 2002).

The signs of learning straining the bounds of disciplines are becoming increasingly obvious in the academy. Interdisciplinary or transdisciplinary programs are a new growth area in higher education as institutions seek to position themselves to meet evolving student needs (Toynton, 2005) as well as more general societal demands (Griffin, 2006). These approaches are also appearing in the k-12 sector as attempts are made to engage students in project-based interdisciplinary learning experiences (Bintz, Moore, Hayhurst, Jones, \& Tuttle, 2006).

\section{Trend 4-learning is moving outside of institutional settings}

With the development of new tools and technologies to support knowledge creation, knowledge gathering, and knowledge sharing, learning is increasingly moving outside of institutional settings established for and dedicated to fostering learning. 
This means that long standing learning organizations such as schools, colleges, and libraries are coming to hold a less exclusive franchise on learning.

Learning opportunities outside of institutional boundaries are developing for individuals at all stages of life. For adolescents still in the k-12 school system there are plentiful learning possibilities outside of school, including access to text-based information from sources around the globe, access to increasingly diverse forms and formats of media, participation in interactive contexts to support the development of projects, the development of mentoring and knowledge-sharing relationships, as well as more structured activity sequences resembling courses (Barron, 2006).

Learning opportunities outside of institutions are becoming more prevalent for all (Roberson, 2006). For example, young adults in traditional community college classes can make use of such outside opportunities to enhance the classroom experience (Berg, 2003). Older retired adults are also taking advantage of selfdirected learning opportunities without institutional support (Roberson \& Merriam, 2005).

Trend 5-learning is coming to span professional and institutional sectors

Just as learning has begun to leap disciplinary boundaries and move beyond institutional settings, so too it has begun to cross over the boundaries between institutional sectors. Individuals located in what might be considered quite different sectors are now more likely to share learning experiences in ways much less likely than in the past.

The multi-sector or trans-sector nature of learning is promoted and facilitated by several key factors. First, there is a growing realization that complex problems often require contributions from multiple sectors with diverse perspectives brought together to formulate the most robust set of solutions (Garland, Hough, Landsverk, \& Brown, 2001; Lindsay, Oleg, \& Coker, 2005; Mathews, 2005). Second, more generally literate populations appear to demand greater visibility into the knowledge base that supports institutional, and expert or professional activities (Tapscott \& Ticoll, 2003). Third, developments in information and computing technologies have created the means for knowledge to be widely shared and accessed across professional and institutional boundaries (McIvor, McHugh, \& Cadden, 2002; Pardo, Cresswell, Thompson, \& Jing, 2006).

Trend 6-learning is moving beyond and between nation states

For most of the past several centuries learning has been moving under the control of nation states as public education systems have grown to encompass more and more of the peoples of the world (Meyer, Ramirez, \& Soysal, 1992). There are powerful reasons connected to the interests of nation states for investing in learning or at least in that part of learning animated by formal education. In the industrial era, nation states have become the dominant players in the growth of learning opportunities through the creation of formal systems of education that have extended schooling to ever greater proportions of the world's population.

The dominance of nation states in the provision of learning opportunities is now being challenged by several developments that have the potential to move learning beyond national boundaries and to insinuate learning between and across such boundaries. First, there are the pervasive effects of new communications 
technologies such as the Internet and satellite television that leap national boundaries despite the efforts of some governments to isolate their peoples from the global flow of information (Martinsons, Ng, Wong, \& Yuen, 2005). These technologies allow information to flow from source to consumer with little or no government mediation. Text, audio, and video move quickly and inexpensively around the globe and by-pass government attempts to control or at least shape the information available to citizens.

Second, there are a growing number of corporate and institutional entities that take as at least part of their mission the development of global networks linking information creators and consumers, roles often played by the same individuals. Among the players seeking a global reach are traditional information providers such as publishers (Cavajal, 1998) and media companies (McChesney, 1999), educational organizations such as traditional and online universities (Currie, DeAngelis, de Boer, Huisman, \& Locotte, 2003; Mason, 1998), as well as institutions less typically associated with the education sector such as the World Bank (Heyneman, 2003).

These developments have already had an impact on shifting the role of national governments from developing the infrastructure for learning through the creation of public education systems, public libraries, and public media to shaping and limiting the infrastructure for learning through policies such as limiting access to Internet resources (Parr \& Thompson, 2006)

Trend 7-learning is moving online

In a variety of ways learning is moving onto the Internet at a pace that would have been difficult to predict even a decade earlier. Not only are more formal and structured educational opportunities, including courses and degree programs, growing at what appears to be an accelerating pace (Allen \& Seaman, 2006), but there is also a proliferation of additional learning opportunities driven by educational institutions, including the hosting of lectures and symposia in virtual online spaces (Foster, 2006), the use of gaming environments for instructional purposes (Childress \& Braswell, 2006), and the transformation of print publications into online learning environments (Horrigan, 2006; Natriello \& Rennick, 2006).

An equally vibrant aspect of the new online learning environment has been the growth of a variety of end-user or learner-driven venues that take advantage of the communications and computing capabilities of the Internet to support collaborative learning. These venues can include collaborative publishing initiatives (Manafy, 2006), virtual communities of practice designed around the needs of a professional group to improve their performance (e.g., Hibbert \& Rich, 2006; Selwyn, 2000) as well as venues driven by social networking opportunities that allow groups such as youth (Lenhart, Madden, \& Hitlin, 2005) interested in their social identity (Boyd, 2006; Donath \& Boyd, 2005) or seniors interested in democratic participation (Fuglsang, 2005) or their own health (Broering, Chuncey, \& Gomes, 2005) opportunities to explore common learning interests.

The movement of learning online is leading to the development of an increasingly robust infrastructure to support additional movement. In the domain of formal education, progress in accreditation, assessment, and general quality control as well as changes in the regulatory landscape to allow online educational providers to receive public funds promise a more stable environment for online education providers. In the domain of user- or learner-driven learning, a new generation of 
social networking and collaboration applications promise an expanding set of learning opportunities.

Trend 8-learning is moving beyond humans to machines

Earlier I noted that learning involved the processes through which organisms or entities gained an understanding that influenced them to change their attitudes and/ or behaviors. With this definition in mind, the growing use of intelligent software agents to learn from information and events in their environments and alter their behavior accordingly qualifies as a growing trend in the learning landscape.

Intelligent agents have been under development by artificial intelligence researchers for some time now with a learning assistant or companion that would assist the learner among the most popular forms (Chan, 1996). The emerging network environment offers some new and enhanced possibilities for such agents (Chou, Chan, \& Lin, 2003). Work has also advanced intelligent agents as tutors or mentors (Baylor, 2004). More generally, intelligent agents have been examined for their use in the provision of automated information services such as information classification (Mukhopadhyay, Peng, Raje, Palakal, \& Mostafa, 2003) as well as more common information sifting tasks such as literature searching (Perez, 2002).

The learning capacity of intelligent software agents is beginning to appear in diverse locations and forms. Not only are such agents available on the Internet via a desktop browser, but they are also available as embedded agents in complex equipment and as stand-alone applications within hardware or what is typically considered a robot.

Trend 9-learning is moving to machine/human blends

Although some learning-dependent tasks are being turned over to intelligent agents, other tasks are being handled by combinations of human and machine learning and labor. These evolving blended learning applications are taking several forms.

In some cases machines are being used to augment human cognition and learning. For example, web-based learning systems can be designed to provide tools to enhance structured learning opportunities and enhance learning (Pedaste \& Sarapuu, 2006). Tools such as handheld computers can also be used to enhance student learning and performance in classrooms (Kuhlman, Danielson, Campbell, \& Topp, 2006). In these situations the machines are used by humans as tools to strengthen learning.

In other cases humans are employed to augment the work of machines as efforts to teach computers to think like humans have given way in some circumstances to efforts that involve humans as part of computer programs. The strategy called intelligence augmentation is to have humans deal with very specific parts of a problem that are difficult for computers, but easy for humans. Perhaps the best contemporary example is Amazon's mechanical turk that lets people with specific tasks connect with those willing to perform the tasks at an agreed price. For example, identifying the title of a piece of music might go for a nickel (Spurgeon, 2006).

Trend 10 - learning is becoming less solitary and more interactive

Learning is more likely to be perceived as involving others in interaction as learning from and with others becomes a larger part of our experience and conception of 
learning. This trend seems to be related to several other mutually reinforcing developments in the post-industrial era.

First, as the proportion of the world's population engaged in research, discovery, and learning increases, the chances that others are engaged in similar learning pursuits increases and makes communication with those others potentially more important, more challenging, and more rewarding. This trend will escalate over time as the transition to the knowledge economy is completed (David \& Foray, 2003).

Second, advances in communications and computing technologies make the process of communicating over great distances in real time possible for more and more learners and reveal to all the population of individuals engaged in like learning and discovery activities (Castells, 1996). As the tools for connecting are developing rapidly, the opportunities for learning in interaction with others are advancing rapidly as well.

Third, specialized environments within the broader pervasive knowledge economy and networked society provide even more enhanced opportunities for learning to be interactive. Such specialized environments include collaborative publications such as Wikipedia, social networking environments such as MySpace, and multi-player gaming environments (Herman, Coombe, \& Kaye, 2006; Manafy, 2006).

Trend 11-learning is becoming less concentrated and more distributed

As some of the trends noted earlier suggest, learning and learning opportunities are becoming less concentrated. The dispersion of learning is taking place at the individual and institutional levels.

First, learning is less likely to be concentrated in single individuals and more likely to be dispersed. Examinations of such distribution patterns of cognition (Hutchins, 1995; Lave \& Wenger, 1991) reveal that learning can occur in highly dispersed ways yet the results from these disparate learning opportunities can be amassed quickly and become the basis for informed action.

Second, learning is less likely to be concentrated within single institutions and more likely to be distributed more broadly. Global centers of learning are being replaced by global networks of learning (Mason, 1998). The same phenomenon is affecting other knowledge bearing social formations such as professional groups. To some extent this is due to general globalization.

Trend 12-our understanding of learning is becoming more biologically connected

In the wake of a concerted effort to enhance our understanding of the structure and functioning of the brain, the prospect of applying new knowledge of the brain to enhance and augment learning is likely to be realized in the coming years. This means that the path forward in the development of learning and the conditions that facilitate it will be informed by a more substantial understanding of the biological basis for learning processes within the human brain. Early indications from this work are consistent with the trends identified here, particularly those related to the diversity of learning, life-long learning, and the contextual and interactive nature of learning. (Hall, 2005; Phillips, 2005). 
Future developments promise continuing progress in understanding brain functions and the implications for learning in general as well as for particular types of what we currently view as learning disabilities. A more provocative and more ambitious view of the future of biology, technology, and learning suggests that exponential technological change is carrying us quickly toward "The Singularity," a time of change so rapid and profound that it leads to a rupture in the fabric of human history promising the merger of biological and non-biological intelligence, softwarebased humans with the potential for immortality, and ultra-high levels of intelligence (Kurzweil, 2005). Whether or not we embrace such an ambitious vision, it is likely to be the case that our understanding of the relationship of biology and learning over the next 50 years will leave our current understanding seeming rather primitive.

\section{Toward emerging discovery networks}

If we consider the 12 trends identified above together, they suggest at least the potential for a fundamental repositioning of learning within society and its professional and institutional structures. Such a repositioning has occurred before as different configurations of institutions assumed different roles and positions in the total learning environment (Cremin, 1976). In the current case both the role of teaching and the role of educational institutions are likely to be subject to substantial change.

\section{Reshaping the role of teaching}

The role of teaching is likely to be reshaped by the evolution of learning along the lines suggested by the 12 trends highlighted earlier. Although there will be much more knowledge about learning and how to facilitate it available, teachers alone will not be the carriers of such knowledge since much of what is being developed works just as well, and in some cases even better, when in the hands of learners themselves. Moreover, to the extent that teachers are trapped in current educational institutions as the site of their practice (more on this below), they may not be working in conditions that permit them to utilize advanced knowledge of learning.

Since teachers will have the opportunity to access a good deal more helpful knowledge about learning, the demands for becoming a state-of-the-art teacher will rise. At the same time the standards for effective learning will rise as learners position themselves in more powerful learning conditions. This means that there will be a good deal of negotiation and experimentation to determine when teaching is most necessary and under which conditions it can be most effective. Such a focusing of the application of teaching will serve to mitigate the damaging effects of the current shortage of high quality teaching that is only likely to grow worse in the face of accelerating demands for enhanced learning across all sectors. This focusing will entail determining the unique value of teaching amid the growing set of more powerful learning tools and environments that can function without teachers.

So what are the dimensions of a reshaped role for teaching? The 12 trends in learning provide a good starting point. The new teacher will need to manage more diverse learning styles with more diverse teaching strategies. The new teacher will need to function outside institutional settings and disciplinary boundaries and orchestrate learning in contexts more relevant to learners and learning tasks. The 
new teacher will need to span professional and institutional sectors, reach beyond national boundaries (Luke, 2004), and operate in face-to-face and online modes. The new teacher will need to manage combinations of human and machine learning as well as learning that is generated through more extensive interactions across more widely distributed settings and rooted in a sound understanding biological processes.

It is difficult to imagine the current teaching force engaged in such a wide range of demanding activities, and that is the point. The role of the new teacher will be dramatically different from those of current teachers. The size of the new teaching force, its recruitment, its preparation, its institutional or extra-institutional base-these all remain to be determined.

\section{Restructuring the role of educational institutions}

To remain in tune with the evolving nature of learning educational institutions will need to be completely restructured. Such restructuring will bear little resemblance to the school reform and restructuring efforts of the last quarter of the 20th century. The major challenge in restructuring educational institutions to correspond with the future of learning will be to determine the role of "educational" institutions in an era when all parts of society are becoming more educational or at least more learning dependent. In such an era the question of what becomes of the specialized role of today's educational institutions looms large.

Once again, we can be guided by consideration of the 12 trends in learning. The new educational institution will need to provide more diverse educational offerings to address diverse learning styles and needs that develop over a lifetime and in multiple sectors or life. The new educational organization will need to offer learning opportunities that are attuned to the diverse backgrounds of learners and that situate learning in contexts that are relevant to the tasks or subjects to be mastered, often extending beyond disciplinary, institutional, professional, and national boundaries. The new educational organization will need to provide or at least coordinate and orchestrate the relations among human and machine learning agents or machine/human blends. The new educational organization will need to facilitate learning that is more interactive over a more distributed range of learning opportunities. Finally, the new educational institution will need to ensure that the educational processes it offers are attuned to the biological determinants of learning.

Current day educational organizations would have great difficulty meeting the requirements of the new educational organization specified here. Although some existing educational organizations may be restructured to meet the new demands, it is just as likely that an entirely new class of educational organizations will rise to the challenge while existing educational organizations atrophy in their performance of state-mandated government sponsored schooling. So while the role of educational organizations will be restructured, it is not clear that existing educational organizations can be restructured.

\section{Discovery networks}

Before closing I feel obligated to offer something a bit more concrete in the way of a vision of the emerging learning landscape. Although the precise contours cannot be specified, it is possible to identify some key elements. 
First, the dominant form for the organization of learning opportunities is likely to be through a combination of research and teaching activities as learners are guided to engage in discovery. This combination will lead to a second key element, problemfocused learning or learning that is oriented around real problems and therefore less divorced and segregated from society. These activities will necessarily be offered not through a central institution, but rather through a network that is dispersed but ultimately organized and coordinated. The network as a dominant form of organization is the third key element of the emerging learning landscape.

The fourth key element will be the infrastructure of software that will serve as a foundation for learning activities across individual, group, institutional, sector, professional, national, and global levels. The software infrastructure will include basic learning activities, agents, and environments as well as the management components to allow them to all work together.

A fifth key element of the discovery networks that will dominate the learning landscape is that they will be multiply nested and operate across interests, life segments, sectors, and configurations of actors and institutions. A sixth element is that these networks will be individually negotiated, perhaps with guidance from teachers. Finally, the discovery networks will come to function on a global level as they naturally extend to encompass all of the relevant knowledge, activities, and actors in a domain.

I stated at the outset that I would employ imagination, information seeking, and invention to begin to assemble a picture of the future of learning that is admittedly speculative while being an extension of current developments and the product of some anticipated deliberate actions. The resulting tour of the future of learning presented here is not the only one that might be expected. I hope that it serves as a point of departure for other efforts to imagine and invent the kind of the future learning landscape that will enrich us all.

\section{References}

Allen, I. E., \& Seaman, J. (2006). Making the grade: Online education in the United States, 2006. Needham, MA: Sloan Consortium.

Ball, A. F. (1995). Community-based learning in urban settings as a model for educational reform. Applied Behavioral Science Review, 3(2), 127-146.

Barron, B. (2006). Interest and self-sustained learning as catalysts of development: A learning ecology perspective. Human Development, 49(4), 193-224.

Baylor, A. (2004). Permutations of control: Cognitive considerations for agent-based learning environments. Journal of Interactive Learning Research, 15(4), 403-425.

Berg, S. L. (2003). Two sides of the same coin: Engaging students beyond the traditional classroom. Community College Enterprise, 9(1), 17-20.

Bintz, W. P., Moore, S. D., Hayhurst, E., Jones, R., \& Tuttle, S. (2006). Integrating literacy, math, and science to make learning come alive. Middle School Journal, 37(3), 30-37.

Boyd, D. (2006). Identity production in a networked culture: Why youth heart MySpace. American Association for the Advancement of Science. St. Louis, MO., February 19.

Bransford, J., Brown, A., \& Cocking, R. (2002). How people learn: Brain, mind, experience, and school. Washington, DC: National Academy Press.

Broering, N. C., Chuncey, G. A., \& Gomes, S. L. (2005). Senior health goes electronic: Partnership on access to health information services. Journal of Consumer Health on the Internet, 9(2), 11-26.

Carolan, B., \& Natriello, G. (2005). Strong ties, weak ties: Relational dimensions of learning settings. Paper presented at the Annual Meeting of the American Educational Research Association, Montreal. 
Castells, M. (1996). The rise of network society: The information age: Economy, society, and culture. Oxford, UK: Blackwell.

Cavajal, D. (1998). Book publishers seek global reach and grand scale. New York Times, 148(51315), C1.

Chan, T. W. (1996). Learning companion systems, social learning systems, and the global social learning club. Journal of AI in Education, 7(2), 125-159.

Childress, M. D., \& Braswell, R. (2006). Using massively multiplayer online role-playing games for online learning. Distance Education, 27(2), 187-196.

Chou, C. Y., Chan, T. W., \& Lin, C. J. (2003). Redefining the learning companion: The past, present, and future of educational agents. Computers and Education, 40(3), 255-269.

Cremin, L. A. (1976). Public education. New York: Basic Books.

Currie, J, DeAngelis, R., de Boer, H., Huisman, J., \& Lacotte, C. (2003). Globalizing practices and university responses: European and Anglo-American differences. New York: Praeger.

David, P. A., \& Foray, D. (2003). Economic fundamentals of the knowledge society. Policy Futures in Education, 1(1), 20-49.

Donath, J., \& Boyd, D. (2005). Public displays of connection. BT Technology Journal, 22(4), 71-82.

Fields, A. W., \& Shelton, A. L. (2006). Individual skill differences and large-scale environmental learning. Journal of Experimental Psychology/Learning, Memory \& Cognition, 32(3), 506-515.

Foster, A. L. (2006). Harvard to offer law course in "virtual world". Chronicle of Higher Education, 53(3), 38 .

Fuglsang, L. (2005). IT and senior citizens: Using the internet for empowering active citizenship. Science, Technology \& Human Values, 30(4), 468-495.

Garland, A. E., Hough, R. L., Landsverk, J. A., \& Brown, S. A. (2001). Multi-sector complexity of systems of care for youth with mental health needs. Children's Services: Social Policy, Research, and Practice, 4(3), 123-140.

Gherardi, S. (2006). Organizational knowledge: The texture of workplace learning. Malden, MA: Blackwell.

Goodfellow, R., \& Lamy, M. (1998). Learning to learn a language-at home and on the web. $\operatorname{ReCALL}, 10(1), 68-78$.

Gorard, S., \& Selwyn, N. (2005). What makes a lifelong learner? Teachers College Record, 107(6), 1193-1216.

Griffin, G. (2006). Balancing agendas: Social sciences and humanities in Europe. Arts and Humanities in Higher Education, 5(3), 229-241.

Hall, J. (2005). Neuroscience and education. Education Journal, 84, $27-29$.

Herman, A., Coombe, R. J., \& Kaye, L. (2006). Your second life? Cultural Studies, 20(2/3), 184-210.

Heyneman, S. P. (2003). The history and problems in the making of education policy at the World Bank, 1960-2000. International Journal of Educational Development, 23(3), 315-338.

Hibbert, K., \& Rich, S. (2006). Virtual communities of practice. In J. Weiss, J. Nolan, J. Hunsinger, \& P. Trifonas (Eds.), International handbook of virtual learning environments (pp. 563-579). Dordrecht, The Netherlands: Springer.

Horrigan, J. B. (2006). Online News. Washington, DC: Pew Internet and American Life Project.

Hutchins, E. (1995). Cognition in the wild. Cambridge, MA: MIT Press.

Ivanitskaya, L., Clark, D., Montgomery, G., \& Primeau, R. (2002). Interdisciplinary learning: Process and outcomes. Innovative Higher Education, 27(2), 95-111.

Jarvis, P. (1994). The church and the learning society. British Journal of Theological Education, 14(2), 136-152.

Kuhlman, W. D., Danielson, K. E., Campbell, E. J., \& Topp, N. W. (2006). Implementing handheld computers as tools for first-grade writers. Computers in the Schools, 22(3-4), 173-185.

Kurzweil, R. (2005). The singularity is near: When humans transcend biology. New York: Viking.

Lave, J., \& Wenger, E. (1991). Situation learning: Legitimate peripheral participation. Cambridge, UK: Cambridge University Press.

Lenhart, A., Madden, M., \& Hitlin, P. (2005). Teachers and technology: Youth are leading the transition to a fully wired and mobile nation. Washington, DC: Pew Internet and American Life Project.

Levin, D. Z., \& Cross, R. (2004). The strength of weak ties you can trust: The mediating role of trust in effective knowledge transfer. Management Science, 50(11), 1477-1490.

Lindsay, N., Oleg, Z., \& Coker, R. (2005). On the European Union's new eastern border: Health promotion, HIV and Ukraine. European Journal of Public Health, 15(4), 336-338.

Lochrie, M. (2004). Family learning: Building all our futures. Leicester, UK: National Institute of Adult Continuing Education. 
Luke, A. (2004). Teaching after the market: From commodity to cosmopolitan. Teachers College Record, 106(7), 1422-1443.

Manafy, M. (2006). The collective wisdom at work. EContent, $29(7), 6$.

Marsick, V. J. (Ed.) (1987). Learning in the workplace. London: Croom Helm.

Martinsons, M. G., Ng, S., Wong, W., \& Yuen, R. (2005). State censorship of the Internet in China. Communications of the ACM, 48(4), 67.

Mason, R. (1998). Globalising education: Trends and applications. New York: Routledge.

Matthews, P. (2005). Multi-sector partnerships for poverty reduction. Engineering Sustainability, $158(1), 5-7$.

McChesney, R. W. (1999). The new global media: It's a small world of big conglomerates. The Nation, 269(18), 11-15.

McIvor, R., McHugh, M., \& Cadden, C. (2002). Internet technologies: Supporting transparency in the public sector. International Journal of Public Sector Management, 15(3), 170-187.

Melaville, A., Berg, A. C., \& Blank, M. J. (2006). Community-based learning: Engaging students for success and citizenship. Washington, DC: Coalition for Community Schools.

Meyer, J. W., Ramirez, F. O., \& Soysal, Y. N. (1992). World expansion of mass education, 1870-1980. Sociology of Education, 65(2), 128-149.

Mukhopadhyay, S., Peng, S., Raje, R., Palakal, M., \& Mostafa, J. (2003). Multi-agent information classification using dynamic acquaintance lists. Journal of the American Society for Information Science and Technology, 54(10), 966-975.

Natriello, G., \& Rennick, M. (2006). An online journal as a virtual learning environment. In J. Weiss, J. Nolan, J. Hunsinger, \& P. Trifonas (Eds.), International handbook of virtual learning environments (pp. 821-848). Dordrecht, The Netherlands: Springer.

Palfreyman, D. (2006). Social context and resources for language learning. System, 34(3), 352-370.

Pardo, T., Cresswell, A., Thompson, F., \& Zhang, J. (2006). Knowledge sharing in cross-boundary information system development in the public sector. Information Technology and Management, 7(4), 293-313.

Parr, M., \& Thompson, C. (2006). Google's China problem (And China's Google problem). New York Times Magazine, 155(53558), 64-156.

Pedaste, M., \& Sarapuu, T. (2006). Developing an effective support system for inquiry learning in a web-based environment. Journal of Computer Assisted Learning, 22(1), 47-62.

Perez, E. (2002). Web search agents: "One-stop shopping” for researchers. Online, 26(2), 22-25.

Perez, S. L., Peon, J. M. M., \& Ordas, C. J. V. (2006). The organizational context of learning: An empirical analysis. International Journal of Technology Management, 35(1), 196-223.

Phillips, J. N. (2005). From neurons to brainpower: Cognitive neuroscience and brain-based learning. ERIC. ED490546

Rees, G., Fevre, R., Furlong, J., \& Gorard, S. (1997). History, place and the learning society: Towards a sociology of lifetime learning. Journal of Education Policy, 12(6), 485-497.

Roberson, D. N., Jr. (2006). Self-directed learning-past and present. Washington, DC. Educational Resources Information Center, ED490435.

Roberson, D. N. Jr., \& Merriam, S. B. (2005). The self-directed learning process of older, rural adults. Adult Education Quarterly, 55(4), 269-287.

Selwyn, N. (2000). Creating a "connected" community? Teachers' use of an electronic discussion group. Teachers College Record, 102(4), 750-778.

Sohn, Y. W., Doane, S. M., \& Garrison, T. (2006). The impact of individual differences and learning context on strategic skill acquisition and transfer. Learning and Individual Differences, 16(1), 13-30.

Spurgeon, C. (2006, November 26). Souls of a new machine - How can you make a computer think like a person? Boston Globe, $\mathrm{C} 2$.

Tapscott, D., \& Ticoll, D. (2003). The naked corporation: How the age of transparency will revolutionize business. New York: Free Press.

Toynton, R. (2005). Degrees of disciplinarity in equipping mature students in higher education for engagement and success in lifelong learning. Active Learning in Higher Education, 6(2), 106-117. 